\title{
Gib mir den Kopf des Pinkertons: Perspectivas teatrais em três processos em ópera
}

MAURICIO SCHWAB VELOSO

Mauricio Schwab Veloso é doutor em artes cênicas pela Friedrich-Alexander Universität Erlangen-Nürnberg (Alemanha). Além disso, ele trabalha como diretor e dramaturgo em teatro e ópera. Entre suas principais linhas de pesquisa estão a transformação do gênero "ópera", a partir da inserção de práticas performativas, a ocupação cênica de espaços urbanos e o uso da memória como ferramenta criativa.

Lattes: http://lattes.cnpq.br/6827637593569433

Orcid: https://orcid.org/0000-0001-8471-3638 


\section{- RESUMO}

Este artigo se propõe a discutir as especificidades do trabalho de atuação dos cantores de ópera a partir de uma experiência de acompanhamento de três processos de ensaio na Alemanha em 2016. Partindo-se da compreensão do canto como uma ação vocal será analisada a possibilidade de se utilizar o processo de aprendizado e internalização da estrutura musical durante a preparação de uma nova partitura para estabelecer uma base de impulsos físicos que podem, graças à sua conexão com o universo ficcional dramatúrgico, servir como ponto de partida para o desenvolvimento do trabalho de atuação.

\section{PALAVRAS-CHAVE}

Ópera, atuação, personagem, cantor.

\section{ABSTRACT}

This essay goes from the experience of watching three rehearsal processes in Germany in 2016 to discuss the specificities of the theatrical work of opera singers. From the understanding that singing is a vocal action, the possibility to use the process of learning and internalizing the musical structure during the preparation of a new role will be analyzed as the establishment of a base of physical impulses that can, thanks to its connection with the fictional universe, work as a starting point for the development of the theatrical work.

- KEYWORDS

Opera, acting, role, singer. 


\section{Introdução}

Como parte de meu doutorado sobre as especificidades do trabalho teatral dos cantores de ópera eu visitei, entre março e abril de 2016, três processos de ensaio em teatros na Alemanha: Die verkaufte Braut (A noiva vendida) de Smetana em Hildesheim (direção de Guillermo Amaya), Madama Butterfly de Puccini em Bonn (direção de Mark Hirsch) e Salome de Richard Strauss em Schwerin (direção de Cornelia Repschlager). Os ensaios de Die verkaufte Braut foram visitados em duas oportunidades (na primeira semana e posteriormente no meio do processo), o acompanhamento de Madama Butterfly se deu na fase dos primeiros corridos separados dos diferentes atos e o processo de Salome foi observado quando ocorriam os últimos ensaios em sala e os primeiros ensaios de palco. Mesmo tendo sido originalmente uma consequência da necessidade de me adaptar às ofertas de cada teatro, essa variação no acompanhamento dos processos me possibilitou observar diferentes aspectos relativos à atuação ${ }^{1}$ dos cantores de ópera, contribuindo para o desenvolvimento de um olhar mais abrangente sobre sua especificidade e permitindo com isso um aprofundamento da reflexão sobre o tema.

Nas próximas páginas serão destacadas e analisadas especificidades do trabalho de atuação dos cantores em cada um destes processos. É importante não perder de vista que tais descrições são o produto do olhar subjetivo de uma pessoa que não está inserida no processo; experiências e opiniões pessoais são inevitáveis nesta constelação e devem ser compreendidas sempre nesta perspectiva. Além disso, como os processos foram acompanhados em fases específicas (e as diferentes fases dos ensaios podem ser muito diferentes umas das outras), deve-se evitar tomar os exemplos descritos como uma versão resumida do processo como um todo; eles representam inevitavelmente uma experiência de ensaio particular, cuja inclusão neste texto é justificada principalmente pela possibilidade de reflexão que eles oferecem (e não por sua relevância dentro do processo, portanto).

A partir da análise independente dos três processos pretende-se iniciar neste ensaio uma discussão sobre a relação entre o aprendizado da estrutura musical e o desenvolvimento da personagem no trabalho dos cantores de ópera, com o objetivo de questionar uma aparente dicotomia do processo criativo que ainda parece persistir na opinião de muitos artistas e pesquisadores. Partindo-se da ideia de que o canto nada mais é do que uma sequência de processos musculares (e, portanto, uma ação) será defendida a tese de que os impulsos corporais constituídos através do aprendizado de uma partitura representam uma base física concreta sobre a qual o cantor pode iniciar a construção do seu trabalho teatral.

\section{Die verkaufte Braut}

A primeira etapa do acompanhamento de Die verkaufte Braut no Theater für Niedersachsen em Hildesheim foi realizada na primeira semana de ensaios; os principais objetivos do trabalho neste momento incluíam aprofundar a compreensão da obra, unificar as diferentes visões sobre as personagens e iniciar a estruturação cênica da concepção do diretor Guillermo Amaya.

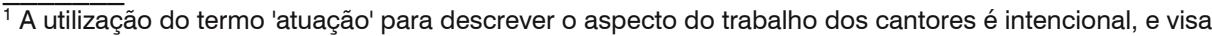
conectá-lo diretamente ao ato (ação), que pode ser considerado como a raiz fundamental do trabalho teatral em estéticas diversas.
}

Ouvirouver Uberlândia v. 15 n. 1 p. 86-98 jan. |jun. 2019 
Para isso eram realizadas frequentemente conversas a respeito das personagens (tanto motivações e objetivos gerais quanto intenções em uma cena específica), buscando-se mergulhar na profundidade emocional de cada figura e desenvolver uma base interna (nas palavras de Amaya, psicológica) para a ação cênica. Paralelamente as primeiras cenas eram improvisadas pelos cantores: a improvisação seguia algumas indicações fornecidas pelo diretor, que podiam ser modificadas (ou mesmo completamente transformadas) em função das motivações e sensações internas dos cantores. Mesmo estando em uma etapa inicial de trabalho, Amaya comentava as improvisações detalhadamente, concentrando-se principalmente na justificativa psicológica de cada movimento e cada frase cantada; os cantores pareciam as vezes um pouco desorientados, mostravam uma certa dificuldade para dominar simultaneamente a partitura, os movimentos cênicos e a emoção interna motivada.

Quatro semanas depois, quando eu retornei aos ensaios, o quadro havia se alterado significativamente: a primeira dificuldade com o domínio simultâneo dos diferentes elementos parecia superada e a profundidade emocional desejada por Amaya era atingida com frequência. Mesmo quando novas cenas eram improvisadas, a postura dos cantores era completamente diferente: eles eram capazes de 'mergulhar' na personagem imediatamente e evocar emoções tanto na ação quanto no canto. Pude constatar o grau desse aprofundamento, por exemplo, em um ensaio da Aria de Marie no terceiro ato, no qual a cantora Arantza Ezenarro se envolveu tão intensamente com as próprias emoções que perdeu o controle e começou a chorar compulsivamente. No mesmo instante algumas perguntas surgiram em minha mente: de que forma um cantor lida com tamanha intensidade emocional? É possível atingir esse envolvimento intenso com as emoções da figura sem comprometer a qualidade técnica do canto? De que forma o cantor equilibra a intensidade expressiva e qualidade da técnica vocal no desenvolvimento de seu trabalho?

A encenação de Die verkaufte Braut foi concebida conscientemente dentro de uma estética realista - uma decisão que influenciou profundamente o desenvolvimento do trabalho dos cantores. Para direcionar e aprofundar a construção das personagens, o diretor Guillermo Amaya utilizava-se de diferentes elementos do trabalho de diretor russo Konstantin Stanislawski, desenvolvendo uma lógica cênica na qual toda ação deveria ter uma motivação e um objetivo coerentes psicologicamente. A construção dessa lógica psicológica era apoiada pela busca do 'movimento correto' (ANTAROWA, 1952, p. 132 et seq.): todas as cenas eram experimentadas e repetidas até que todos estivessem convencidos de que as ações e os movimentos fossem a melhor codificação possível das motivações das diferentes personagens, permitindo um aprofundamento emocional através da conexão entre esse 'mundo interior' (emocional e psicológico) e a cena.

O trabalho vocal era desenvolvido de modo semelhante: Amaya partia do pressuposto de que a corporificação das intenções e o aprofundamento das emoções (sempre baseados na motivação psicológica da personagem) provocariam uma transformação 'espontânea' da voz; ao mesmo tempo, entretanto, o diretor musical Werner Seitzer trabalhava detalhadamente na 'Gestaltung des Aisdricks' (a formalização da expressão vocal), na qual - a partir da experimentação de diferentes possibilidades de composição de nuances nas linhas vocais - a melhor forma de destacar à relação entre a motivação da personagem e a estrutura musical definida 
pelo compositor era escolhida objetivamente pelos cantores e pelo maestro. Analogicamente ao desenvolvimento do trabalho corporal, portanto, deveria existir uma base concreta (física) que auxiliasse a definição da expressão; ela, entretanto, não bastava para a construção completa da personagem, pois apenas através de seu 'preenchimento' essa forma poderia conquistar a intensidade emocional desejada.

Como os cantores realizavam esse 'preenchimento'? Para Amaya, quanto mais o cantor conseguisse resgatar e desenvolver em si as emoções através das quais ele constrói a personagem, mais 'verdadeiras' (preenchidas emocionalmente) se tornariam as ações que ele executa, tornando maior a probabilidade de que o espectador 'acreditasse' nelas. Esta crença pressupõe, entretanto, que a capacidade do cantor de gerar determinados sentimentos implica na percepção desses sentimentos pelo espectador em gênero e grau similares, o que parece difícil de ser defendido objetivamente, pois ignora que o processo de comunicação apresenta outras interferências e ruídos que tornariam tal transmissão direta dos sentimentos uma utopia.

Além disso, esta crença esbarra nas fronteiras da própria situação de representação, pois tal envolvimento levaria em última instância a uma fusão completa entre o cantor e o universo da figura que ele representa, que lhe impossibilitaria perceber a situação de representação como tal (ANTAROWA, 1952, p. 119 et seq.). Tamanha fusão é naturalmente inviável na prática - como nos mostra a cena de Ezenarro descrita anteriormente: quando a cantora é contaminada profundamente demais pelas emoções de sua personagem (e chora), passa a ser impossível continuar a cantar com a qualidade e o controle técnicos necessários. Tendo em vista a importância da execução perfeita (do ponto de vista técnico) dentro da percepção do espectador como um todo e do grau de dificuldade técnica que a maioria das partituras oferece, parece difícil imaginar que tal grau de envolvimento seja atingível (e mesmo desejado) pelos cantores.

A soprano, como a maior parte dos cantores com quem conversei ao longo do último ano, parece trabalhar nesse sentido em uma espécie de 'êxtase controlada', que Ihe possibilita mergulhar profundamente nas emoções geradas tanto pela música quanto pelo universo da personagem sem abrir mão da qualidade de seu desempenho técnico, potencializando a capacidade comunicativa tanto da estrutura musical quanto da dramatúrgica. O tenor Jonas Kaufmann define o conceito da seguinte maneira:

O cantor tenta convencer não apenas ao público, mas também a si mesmo, de que se tornou a figura que está representando naquele momento. [...] Isso é muito bonito e intenso, porque você vive nessa ilusão, nesse sonho; mas é ao mesmo tempo uma situação complicada, porque você está na beira da esquizofrenia. Por isso existe um mecanismo de controle inconsciente, que protege você de problemas, seja para que você não se machuque em cena porque bateu muito forte na mesa ou para que você não faça algo nocivo vocalmente porque está sobre esta pressão. Êxtase controlada significa, portanto, que é possível alcançar o êxtase sem perceber que você tem alguém dentro de você capaz de 'puxar a tomada' em uma situação de emergência, como eu costumo dizer." (LORBER, 2016, p. 127) (tradução nossa). ${ }^{2}$ 
O acompanhamento seguinte me permitiu, a partir de vivência de um processo de ensaios por uma perspectiva quase oposta à de Hildesheim, continuar e aprofundar esta discussão sobre a relação entre a execução da partitura musical e o desenvolvimento emocional da personagem dentro do trabalho dos cantores.

\section{Madama Butterfly}

O acompanhamento do processo de Madama Butterfly no Theater Bonn foi realizado durante a quarta semana de ensaios - próximo do meio do processo, portanto. Nesse período tive a oportunidade de assistir à marcação do terceiro (e último) ato e a corridos separados dos três atos, o que me possibilitou investigar novas facetas do trabalho de atuação dos cantores, como o desenvolvimento da personagem ao longo das diferentes cenas e a necessidade de domínio técnico de sequências mais longas através de uma alternância de momentos de economia e de liberação de energia.

Diferentemente de Hildesheim, em Bonn falou-se pouco de psicologia, motivação ou emoção. Mark Hirsch, o diretor, tinha uma imagem clara de como e quando as personagens deveriam se mover e utilizava os ensaios em grande parte para traduzir essa imagem para os cantores - para quem era delegada a responsabilidade de preenchimento emocional dessa marcação. Nesse sentido havia muita liberdade para experimentar diferentes motivações (e sensações) e compor, a partir destas, uma base emocional para as ações cênicas propostas por Hirsch; o feedback fornecido pelo diretor, entretanto, era bastante econômico: enquanto as ações, movimentos e posições eram observados detalhadamente durante os corridos (e corrigidos posteriormente), comentários sobre os efeitos de determinada proposta ou indicações de possíveis caminhos eram raros nas conversas ao final dos ensaios.

É difícil definir até que ponto essa 'liberdade' dos cantores representa uma característica do processo como um todo ou apenas a imagem do momento em que o acompanhei. É possível se imaginar, nesse sentido, que Hirsch desejasse primeiro construir detalhadamente a sua imagem do espetáculo (oferecendo uma certa liberdade para que os cantores investigassem suas emoções e as conectassem com a estrutura cênica), voltando o foco posteriormente para o trabalho de atuação através do aprofundamento das personagens e suas motivações.

O trabalho com Kathrin Leidig - que eu pude acompanhar desde o começo, pois como Kate Pinkerton ela canta apenas no terceiro ato - parece confirmar (ao menos parcialmente) esta perspectiva de análise. Antes do primeiro ensaio de sua cena, Hirsch e ela tiveram uma longa conversa, na qual o diretor descreveu claramente a sua visão (emocional) da personagem e a forma como planejava concretizá-la cenicamente. Nos ensaios seguintes a atuação de Leidig foi comentada mais intensamente, até que o diretor (aparentemente) considerasse que o trabalho de

\footnotetext{
${ }^{2}$ No original: Der Sänger versucht, nicht nur das Publikum, sondern auch sich selbst glauben zu machen, er wäre die Figur auf der Bühne, die er gerade darstellt [...] Das ist sehr erfüllend und sehr schön, weil man in diesem Traum, in dieser Illusion lebt. Aber es ist eine Grauwanderung, denn man ist knapp an der Grenze der Schizophrenie. Es gibt dann einen unbewussten Kontrollmechanismus, der einen vor Schäden schützt, und sei es nur, dass man sich auf der Bühne nicht wehtut, weil man zu fest auf den Tisch haut, oder sei es, dass man sich stimmlich nichts antut, weil man einfach so unter diesem Druck steht. Kontrollierte Ekstase bedeutet also, dass man selbst ekstatisch empfindet, ohne zu merken, dass man tief im Inneren doch jemanden hat, der notfalls den Stecker zieht, wie ich immer sage. (LORBER, 2016, p. 127).
} 
atuação se encaminhava na direção proposta e diminuísse consequentemente a frequência dos feedbacks. A partir desta observação passei a supor que todos os cantores teriam passado por um acompanhamento mais presente do processo criativo no início dos ensaios, ou seja, que seu trabalho possuía um direcionamento emocional claro, mesmo que para um observador externo pudesse parecer (no momento em que acompanhei os ensaios) que eles trabalhavam sem orientação.

De maneira geral, o processo de ensaios de Madama Butterfly parece poder ser descrito como uma tentativa de comunicar de forma clara e objetiva a imagem pré-concebida que o diretor possuí do espetáculo e das personagens. Os cantores, por sua vez, devem durante o processo encontrar uma conexão entre suas próprias emoções e a ação cênica definida pelo diretor, levando a um preenchimento emocional que permita que os espectadores (durante as apresentações) possam 'acreditar' nessa estrutura da encenação (o que se torna o objetivo buscado por Hirsch ao construir o espetáculo em uma estética realista).

Nesse sentido o processo parece representar o oposto do que eu havia observado em Hildesheim, aonde Amaya era mais flexível a propostas e modificava frequentemente a marcação, se um cantor considerasse isso importante para o aprofundamento de sua atuação. Ao mesmo tempo, enquanto Amaya trabalhava insistentemente sobre o preenchimento emocional das ações e buscava sempre se assegurar que os cantores possuíam uma motivação clara para aquilo que faziam ou cantavam, Hirsch se mostrava mais flexível neste aspecto, permitindo que os cantores desenvolvessem mais livremente sua atuação e a concretização das emoções na forma pré-definida.

Mesmo que eu não tenha tido a oportunidade de assistir aos dois espetáculos prontos, e portanto de relacionar o desempenho cênico dos cantores com as características do processo do qual eles participaram, a estratégia utilizada por Hirsch me parece arriscada, pois ela pressupõe a capacidade dos cantores de trabalhar autonomamente para concretizar etapas importantes do desenvolvimento da personagem. Se com Amaya alguns cantores pareciam - em um primeiro momento - além de sua capacidade de lidar com o excesso de informações cênicas, técnicas e musicais, com Hirsch eles se mostravam muitas vezes perdidos, com pouco ou nenhum traço de uma personagem, divididos entre a realização da forma e as emoções presentes na música

Por outro lado, se em minha segunda visita a Hildesheim eu pude verificar um grande desenvolvimento dos cantores em relação à sua capacidade de lidar com o excesso de informações, é possível se supor que, se eu tivesse oportunidade de voltar a Bonn em um momento posterior do processo, eu verificasse que essa dificuldade havia sido pelo menos parcialmente superada pela maior parte dos cantores. De maneira geral eu diria que cada cantor possui um ponto de equilíbrio diferente entre a liberdade para criar a personagem e a necessidade de impulso do diretor ou maestro: se alguns cantores parecem reagir melhor quando podem desenvolver seu trabalho muito livremente (porque tem uma visão clara da personagem e trazem muitas ideias sobre como concretizá-la), outros trabalham melhor quando acompanhados de perto por um diretor (pois se adaptam rapidamente ao conceito da encenação e tem a capacidade de concretizar a visão de um outro e conectá-la com seu próprios impulsos); os primeiros, por outro lado, podem entrar 
rapidamente em conflito com um diretor que tem um ponto de vista diferente, enquanto os últimos podem encontrar dificuldade em criar algo consistente quando o diretor não lhes fornece informações suficientes.

Dentro da comparação entre os dois processos considero interessante observar ainda que exatamente em um processo que parte de uma obra cuja estética musical e dramatúrgica preza tanto a construção lógica de um universo real (o caso de Madama Butterfly) se tenha dado pouca importância à construção desta lógica dentro do trabalho dos cantores, enquanto em um processo desenvolvido a partir de uma estrutura musical não realista (caso de Die verkaufte Braut) a construção psicológica das personagens tenha se mostrado como um dos focos principais do desenvolvimento da atuação. Esta constatação me levou a alguns questionamentos: até que ponto a ligação entre a estrutura musical e a estética da encenação é importante para o desenvolvimento do trabalho de atuação? Um cantor consegue aprofundar o trabalho sobre a personagem apesar de uma possível oposição entre a estética implícita na partitura e a estética da encenação? É possível, nesse caso, que o cantor encontre uma maneira de conectar essas duas esferas aparentemente opostas no desenvolvimento de seu trabalho e consiga, dessa forma, superar tal oposição? O acompanhamento dos ensaios de Salome no Mecklenburgis Staatstheater em Schwerin possibilitou (em virtude da complexidade das estruturas musicais na obra de Richard Strauss e a sua influência no processo criativo) o aprofundamento desta discussão.

\section{Salome}

A base da marcação de todo o espetáculo já estava pronta quando eu visitei os ensaios de Salome em Schwerin, o que possibilitou que eu acompanhasse o detalhamento do trabalho de atuação nas diferentes cenas e nos primeiros ensaios no palco com o cenário definitivo. Durante este período foi especialmente interessante vivenciar a forma como os cantores trabalhavam para dominar as complexas estruturas musicais de Salome e estabelecer relações entre estas estruturas, seu trabalho de atuação e a construção cênica que vinha sendo desenvolvida.

Como em Hildesheim, as discussões e experimentações sobre motivações e intenções das diferentes personagens constituíam uma parte importante dos ensaios - nesse caso, para permitir a intensificação emocional de suas ações e das relações entre elas. Também havia espaço para que as ações fossem questionadas e modificadas quando se verificava um descompasso entre a ação e a motivação que a deveria preencher, ou seja, havia uma preocupação de que toda ação tivesse uma motivação psicológica definida (ainda que isso, como discurso, não fosse tão claramente expressado como por Amaya).

Esta presença implícita de um discurso psicológico a respeito das personagens significa que a atuação dos cantores em Salome era 'concebida' (ainda que talvez não tão conscientemente) dentro de uma estética realista baseada em uma construção lógica e coerente de personagens, relações e ações. Em determinados momentos, entretanto, a encenação de Cornelia Repschlager ultrapassava os limites deste realismo e criava imagens quase expressionistas, levando ao surgimento de uma 'realidade paralela' por um curto período de tempo. Mesmo que para um ob- 
servador externo como eu fosse difícil em um primeiro momento determinar o conceito de encenação no qual se baseava a introdução destas quebras, pude verificar imediatamente que sua existência era determinante para o desenvolvimento do trabalho dos cantores, pois implicava no estabelecimento de duas qualidades paralelas de atuação com características estéticas distintas.

De acordo com o que era discutido a esse respeito durante os ensaios ficava a impressão de que Repschlager buscava com tais momentos uma intensificação emocional da ação cênica - e não propriamente um estranhamento intencional do realismo; estes momentos deveriam (idealmente) ser percebidos pelos espectadores organicamente ${ }^{3}$ dentro da linha de desenvolvimento da personagem, possibilitando um aprofundamento no seu envolvimento com a encenação através de uma intensificação da camada sensorial do processo de comunicação. Para tanto, os cantores teriam que encontrar uma maneira de possibilitar a integração destas ações 'expressionistas' dentro de sua lógica interna, de tal forma que o espectador não percebesse a existência das diferentes estéticas e pudesse acompanhar a encenação como se se tratasse de um conjunto coerente em si.

Como os cantores lidavam com esta dificuldade? De acordo com a minha percepção durante o acompanhamento dos ensaios de Salome, a estrutura musical oferecia uma alternativa para o desenvolvimento de uma lógica unificada para a ação cênica, funcionando dessa forma como um ponto de apoio importante para a superação as quebras e integração dos momentos 'expressionistas' dentro da encenação. Considerando-se o canto como uma ação física (pois sua concretização se dá essencialmente através de uma sequência de processos musculares), podese supor que, através da simples execução da estrutura musical da partitura sejam gerados uma série de impulsos internos conectados entre si, que podem ser direcionados para um desenvolvimento 'orgânico' da ação cênica - independentemente da lógica dramatúrgica de uma personagem.

Dois aspectos tornam essa hipótese especialmente interessante nesta investigação sobre o trabalho de atuação dos cantores de ópera. Primeiramente, é necessário lembrar que em virtude da complexidade das estruturas musicais os cantores trabalham durante meses sobre a partitura e (idealmente) iniciam o processo de ensaios com a estrutura musical completamente decorada e internalizada; utilizar os impulsos oriundos da execução musical para a construção cênica possibilita nesse sentido integrar o processo de preparação musical no desenvolvimento da encenação, rompendo uma possível divisão entre a lógica das estruturas musical e cênica. Considerando-se que a maior parte das partituras é composta como uma tradução do universo dramatúrgico em forma musical, esses impulsos ligados ao canto estariam intrinsecamente ligados à estrutura dramatúrgica - de tal forma que o aprofundamento sensorial gerado por eles também representaria um mergulho no universo ficcional (servindo naturalmente como uma base para o desenvolvimento do trabalho de atuação).

Além disso, esta nova possibilidade de percepção da relação entre as estruturas musical e dramatúrgica possibilita uma reflexão diferenciada a respeito da importância da técnica vocal (bem como da execução musical 'perfeita') dentro do

\footnotetext{
3 "Para não me alongar no conceito de 'organicidade' neste ensaio, indico apenas que me refiro aqui ao conceito desenvolvido pelo diretor polonês Jerzy Grotowski, no qual uma ação se torna orgânica ao nascer diretamente de um impulso físico - sem que haja um comando racional determinando sua execução.
} 
trabalho de atuação. Partindo-se de uma obra como Salome - aonde a estrutura musical se constitui como uma camada autônoma repleta de detalhes e desafios que exige frequentemente uma concentração absoluta na técnica de emissão vocal - poderia se imaginar à primeira vista que a mera execução desta estrutura representaria um obstáculo no desenvolvimento de uma atuação orgânica por parte dos cantores, pois a constante evocação racional da técnica impediria o desenvolvimento de uma qualidade de atuação na qual a 'superação' do controle racional sobre a ação é fundamental. Um olhar mais aprofundado, entretanto, oferece uma outra possibilidade para se observar este aparente paradoxo: a possibilidade de utilização dos impulsos físicos gerados pela voz como base para o desenvolvimento do trabalho de atuação serve como prova da existência de uma relação intrínseca entre o canto e a ação cênica, que por sua vez implica na superação desta suposta divisão entre a reprodução técnica da estrutura musical e a interpretação musical e teatral desta estrutura.

A partir desta perspectiva pode se afirmar que o trabalho de estudo e internalização da estrutura musical é ao mesmo tempo um trabalho sobre a técnica e sobre a estrutura dramatúrgica, pois possibilita a criação de uma rede de impulsos físicos que serve como base para o aprofundamento da interpretação desta estrutura. Do mesmo modo, o trabalho sobre a personagem durante os ensaios possibilita a transformação e o aprofundamento da rede de impulsos desenvolvida durante o trabalho de preparação, contribuindo para o aprimoramento técnico e para a intensificação da capacidade expressiva da estrutura musical.

O que torna esta perspectiva de análise especialmente interessante é sua capacidade de romper a ideia de que o investimento na qualidade técnica ou na profundidade dramática representaria necessariamente uma perda no processo de comunicação como um todo: mesmo que em um determinado momento de uma apresentação seja necessário focalizar especialmente uma destas estruturas (por exemplo para que se cante uma passagem especialmente complexa ou se realize uma cena emocionalmente intensa), o que ocorre é apenas uma mudança do foco consciente da ação. Se o impulso musical e o impulso cênico se encontram em um tipo de relação que poderíamos denominar simbiótica, não há perda de qualidade musical ou cênica com tal mudança de foco, pois a execução perfeita de uma determinada passagem é a porta de entrada para um aprofundamento emocional desse mesmo instante, que por sua vez reverbera na estrutura musical e transforma sua execução.

\section{Conclusão - o canto como ação orgânica}

Seria possível estender esta possibilidade de percepção dos impulsos vocais como base de desenvolvimento do trabalho de atuação aos outros processos que acompanhei? Considerando-se que Puccini trabalhava em suas obras a partir da possibilidade de encontrar um discurso musical construído para se adequar plenamente às necessidades de uma estrutura dramatúrgica realista (permitindo a construção de uma realidade cênica que espelhasse o mundo 'real') estabelecer uma ligação orgânica entre a estrutura musical e a teatral em uma obra como Madama Butterfly não deveria ser um desafio especialmente complexo para os canto- 
res: se a música é composta como uma elaboração do universo sensorial da dramaturgia, os impulsos do canto devem ser em sua maioria conectados essencialmente aos impulsos da personagem, suas motivações e ações. Dessa forma, através do estudo, repetição e internalização da partitura, devem ser ativados determinados processos físicos relevantes também para o desenvolvimento do trabalho de atuação.

A estruturação musical e dramatúrgica de Die verkaufte Braut, por outro lado, dificilmente pode ser compreendida dentro dos limites de uma estética realista: ainda que o desenvolvimento geral das personagens siga uma lógica que pode ser compreendida como uma tentativa de espelhamento do mundo 'real', a divisão clara entre recitativos e 'números' (árias, duetos, etc., nos quais poucas frases são repetidas várias vezes durante alguns minutos) cria uma lógica essencialmente artificial, muito mais conectada com uma determinada estética musical do que com uma tentativa de espelhamento realista de um universo; por conta disso, o estabelecimento de uma ligação orgânica entre o aprendizado da partitura e o desenvolvimento da personagem pode se tornar mais complexo para os cantores.

Analisemos estas duas estruturas em separado: no caso dos recitativos, a possibilidade de encontrar tal conexão parece ser mais simples, pois eles são compostos na maior parte dos casos em relação direta com a linguagem falada e tendem dessa forma a conectar intuitivamente os impulsos musicais e os impulsos dramáticos. Além disso, os cantores possuem (na maior parte das vezes) uma certa liberdade na execução dos recitativos - podendo relativizar o tempo de uma pausa e mesmo alterar levemente a linha melódica proposta - o que facilita a transformação dos impulsos musicais em função das necessidades da cena. É possível se imaginar, portanto, que a conexão entre os impulsos gerados pelo aprendizado da partitura e os impulsos resultantes do desenvolvimento emocional da personagem ocorra quase naturalmente, pois a estrutura musical é desenvolvida em função da dramatúrgica e pode ser readaptada pelos cantores em função da motivação da personagem ou da estrutura cênica construída.

É nas arias e números como duetos e tercetos que a situação se torna especialmente complexa: tendo em vista que estes números frequentemente expressam pensamentos ou motivações que não seriam manifestados em voz alta em um contexto real, torna-se necessário buscar conscientemente uma alternativa para conectar de forma orgânica os impulsos musicais ao universo dramatúrgico (que não dependa da lógica realista). Nesse caso (pelo menos foi o que observei em Hildesheim) a própria estrutura musical acaba se transformando em uma base autônoma para a organização dos sentimentos: se as árias, duetos, etc. podem ser compreendidos como um momento de explosão de sentimentos no meio de uma estória, uma espécie de buraco no tempo realista (e essa parece ser uma opinião geral no meio), a estrutura musical gera uma possibilidade concreta de organizar e apresentar estes sentimentos ao espectador. Nesse sentido, pode se dizer que a partitura não serve à estrutura teatral (como nos recitativos), ela constitui essa estrutura.

Dessa maneira, é possível novamente estabelecer uma conexão entre os impulsos resultantes do aprendizado da partitura e os impulsos cênicos, assumindo os números como quebras dentro de uma lógica dramatúrgica realista e conectan- 
do-os aos recitativos através do desenvolvimento de uma rede orgânica de impulsos físicos ligados tanto à lógica da estrutura musical quanto ao desenvolvimento emocional da personagem. Com isso, mesmo em uma estrutura dramatúrgica e musical como Die verkaufte Braut torna-se possível superar uma possível dicotomia entre os impulsos oriundos da construção da personagem e aqueles provenientes do aprendizado da partitura, permitindo aos cantores o aprofundamento emocional de sua atuação através do desenvolvimento de uma conexão orgânica entre a expressividade musical e a constituição dramática.

Esta possibilidade de se compreender a estrutura musical como uma base para o desenvolvimento do trabalho de atuação permite ainda que se questione uma outra dicotomia presente com relativa frequência no discurso dos artistas: que precisão técnica e força expressiva representariam necessariamente dois polos opostos dentro do desenvolvimento do trabalho dos cantores. Considerando-se o domínio da técnica vocal como a primeira etapa deste estabelecimento de uma rede de impulsos físicos necessários para a concretização do canto, o que ocorre dentro do processo de criação de uma personagem específica é um duplo processo de adaptação. Em um primeiro momento são selecionados e aprimorados, dentro desta grande base técnica, aqueles impulsos necessários à execução técnica perfeita de uma estrutura musical específica. A repetição intensiva desta estrutura (durante o processo de preparação) leva a uma automatização destes impulsos, que passam a poder ser ativados sem necessidade de um comando consciente. Tal repetição, ao mesmo tempo, inicia outros processos internos que possibilitam um envolvimento sensorial com a estrutura musical e servem como uma primeira aproximação à estrutura dramatúrgica (na qual a partitura em maior ou menor grau se inspira). Quando se iniciam os ensaios, por fim, essa base selecionada e internalizada de impulsos serve para dar início ao processo de desenvolvimento da personagem que, por sua vez, possibilita uma segunda transformação desta base de impulsos, levando a um novo aprofundamento do envolvimento com a estrutura musical e depuração da técnica.

Resumindo: o domínio de uma partitura do ponto de vista musical oferece ao cantor uma base para o desenvolvimento de seu trabalho de atuação, pois gera impulsos corporais que podem ser aproveitados para o aprofundamento de aspectos emocionais da personagem e para o desenvolvimento e aprimoramento das ações cênicas. Durante o trabalho sobre a encenação estes impulsos sofrem uma nova transformação em função da vivência corporal das situações dramatúrgicas propostas que permite por sua vez uma intensificação emocional da expressão e possibilita o 'preenchimento' das formas musicais pré-definidas na partitura e delineadas pelos cantores. Um movimento constante de adaptação, que permite aos cantores unirem técnica e expressividade, consciência e intuição, voz e corpo, impulso e forma, de maneira simbiótica no desenvolvimento de seu trabalho. 


\section{REFERÊNCIAS}

ANTAROWA, K. Studioarbeit mit StanisIwaski: Dreißig Gespräche über System und Elemente schöpferischer Arbeit und fünf Gespräche über die Arbeit an der Oper, Werther' von Massenet. Berlin: Verlag Bruno Henschel und Sohn, 1952.

LORBER, Richard. Oper, aber wie!? Gespräche mit Sängern, Dirigenten, Regisseuren, Komponisten. Köln: Bärenreiter Verlag, 2016.

POLLASTRELLI, CARLA E FLASZEN, LUDWIG (org.) O Teatro Laboratório de Jerzy Grotowski 1959 1969. São Paulo: Edições SESC - SP; Editora Perspectiva, 2007.

STANISLAVSKI, CONSTANTIN. A construção da personagem. Rio de Janeiro: Civilização Brasileira, 1976.

Recebido em 04/04/2018 - Aprovado em 23/04/2019

Como citar:

Veloso, M. (2019). Gib mir den Kopf des Pinkertons: Perspectivas teatrais em três processos em ópera. OuvirOUver, 15(2), 86-98. https://doi.org/10.14393/OUV24-v15n1a2019-6

(c) (†) A revista ouvirOUver está licenciada com uma Licença Creative EY NC Commons Atribuição-NãoComercial 4.0 Internacional. 